Japanese Psychological Research

1081, Vol. 23, No. 4, 191-195

\title{
A study of attack patterns: Equity or recency?
}

\author{
KENNICHI OHBUGHI \\ Department of Psychology, Faculty of Education, Osaka Universily of Education, Tennoji-ku, Osaka 543
}

The present study was designed to examine if equity or recency of attack is a more powerful factor in determining magnitude of retaliation. Twenty-two Japanese male university students were asked to compete with male opponents for reaction time. Then, based upon their performance, the subjects were electrically attacked by the opponents either in an increasing shock pattern or a decreasing shock pattern, with the averaged shock level held constant. After receiving attack, the subjects were allowed to retaliate by delivering shocks to the opponents. The recency hypothesis predicted that the subjects would retaliate more intensely in the increasing attack condition than in the decreasing condition. However, the results favoured the equity view in that the subjects' total shock delivery was almost equal in both conditions. Unexpectedly, the subjects rated the opponents who had decreased attack as more malicious than those who had increased it.

Key words: attack patterns, retaliation, recency effect, equity-restoring, male students, competitive aggression paradigm.

An attack is considered to be an important social instigator of aggression. Reactions to attack have been investigated by using Taylor's (1967) competitive aggression paradigm. Research has consistently found that various attack patterns tend to evoke the corresponding counterattack from both male victims (Dengerink, O'Leary, \& Kasner, 1975; Epstein \& Taylor, 1967; Ohbuchi, 1979) and female victims (Gaebelein, 1978; Ohbuchi \& Oku, 1980). That is, increasing attack is responded to by the victim with increasing aggression while decreasing attack reduces the victim's aggression, and constant attack evokes a constant level of aggression.

This reciprocal retaliation tendency has been explained from several points of view: (a) Some researchers imply an equity concept that the matching of the victim's aggression to attack seems to reflect his attempt to maintain or restore equity in harm between him and

1 The author wishes to express gratitude to Dr. Edward Moss of State University of New York for his critical reading of the manuscript and valuable comments. his attacker (Gaebelein, 1978; Ross, Thibaut, \& Evenbeck, 1971). (b) O'Leary and Dengerink (1973) asserted a recency effect; the intensity of the most recent attack is a major determinant of retaliation. This view seems to be based on attributional considerations, such that the most recent behavior of the attacker is salient and thus most informative for the victim to infer the attacker's aggressive intent (Taylor \& Fiske, 1978). (c) The last view is that the victim's retaliation is attempted in the hope of controlling the future behavior of the attacker (Dengerink, 1976). Zillman (1979) also admits that aggressive behavior is often motivated by the desire to control harmful events, that is, by the need to reduce present harm and to prevent future harm.

The present study was designed to examine if equity or recency is a more potent factor in determining the magnitude of retaliation. For this purpose, Taylor's paradigm was modified. The reason is that, in the standard procedure; (a) the equity view and the recency view make the same predictions about the victim's retaliation so that the effects of 
these factors cannot be differentiated, and (b) difficulty in eliminating subjects' need for control makes these less visible. In the present experiment, such problems were solved by separating competition, attack, and retaliation into different sessions. Thus, a subject was asked to exchange shocks with an opponent after the competition session according to their total outcomes of competitions. The opponent first attacked the subject in either an increasing or decreasing manner, with the averaged level held constant. The subject was then given opportunities to retaliate. It is reasonable to assume that since the subject was informed that he would no longer be re-attacked, his retaliating behavior would be little affected by desire to control the opponent's future attack.

If the recency of attack determined retaliation, the subjects who received the increased attack would deliver more intense shocks to the opponent than the subjects who received the decreased attack. On the other hand, the equity view predicts that the subjects would decide the magnitude of retaliation by depending upon the total amount of attacks and hence their shock delivery would not significantly differ between these conditions.

\section{Method}

Subjects. The subjects were 22 male Japanese university students enrolled in introductory psychology classes. They contacted via telephone by the experimenter and asked to participate in this experiment.

Apparatus. The task board for the subject contained a reaction key, a pair of win and lose lights, a set of five feedback lights numbered from 1 to 5 , and a set of five shock buttons numbered from 1 to 5 . The test stimulus for reaction was a luminous circle of $18 \mathrm{~mm}$ diameter built into the wooden screen in front of the subject.

Procedures. The subject was introduced by the experimenter into a small partition in the experimental room and sat at the table which held the task board. The male confederate opponent, whom the subject was led to believe was another subject, had taken up his position in advance in the adjoining partition. The subject and the opponent remained anonymous and could not see each other either during or after the experiment. They were informed of the use of electric shock and of their right either to refuse to participate or stop the procedures at any time. If they agreed to participate, the shock electrodes were attached to their right fingers. The subject and the opponent were then given a series of shocks that increased in voltage. They were asked to report when they first noticed these shocks and when they reached a level that was definitely unpleasant and that they did not wish to exceed.

The present procedure consisted of three sessions: competition, attack, and retaliation. The task instructions were given via tape recorder. The subject and the opponent were informed that they would compete with each other for reaction time and then they would exchange shocks in proportion to the outcomes of the competition session. In the competition session, the subject and the opponent were asked to react to the test stimulus by releasing their reaction keys as rapidly as possible. Immediately after reacting, either the win light or the lose light was illuminated to indicate whether the subject won, lost, or drew the competition trial. After fifteen competition trials, every subject was told by the experimenter that he had lost six trials but won five trials, and he had drawn four trials. $\mathrm{He}$ was further told that, accordingly, he would receive shocks six times from his opponent and then he 
Table 1

Mean intensities of shocks delivered by subjects as a function of attack patterns and shock trials

\begin{tabular}{cccccccc}
\hline \multirow{2}{*}{ Attack pattern } & \multicolumn{7}{c}{ Shock trial } \\
\cline { 2 - 7 } & & 1 & 2 & 3 & 4 & 5 & Total \\
\hline \multirow{2}{*}{ Increasing } & $M$ & 2.91 & 2.09 & 4.09 & 2.82 & 4.09 & 16.0 \\
& $S D$ & 0.90 & 0.79 & 0.79 & 1.75 & 1.08 & 1.92 \\
Decreasing & $M$ & 2.91 & 3.09 & 3.09 & 3.73 & 2.82 & 15.64 \\
& $S D$ & 1.00 & 1.16 & 1.24 & 1.54 & 1.27 & 2.58
\end{tabular}

could deliver shocks five times to his opponent. The reason why the numbers of wins and losses were not equal was to avoid having the subject suspect that the competitions were artificial.

There were five different shock intensities. The subject was informed that the button 4 shock corresponded to an intensity judged as definitely unpleasant during the presession threshold measurement and that the lower intensities (buttons 3,2 , and 1) were each $2 \mathrm{~V}$ weaker than the next higher intensity. The button 5 shock was described as a $2 \mathrm{~V}$ stronger shock than the button 4 shock, though its actual intensity was equal to that of the button 4 shock. In the attack session, every subject was given shocks six times by the opponent and he was informed through the feedback lights how intense the shocks were. Then, in the retaliation session, the subject was given opportunities to retaliate by pressing shock buttons five times.

The opponent's shock pressing constituted the experimental manipulation of attack. In the increasing condition the opponent increased shock intensities as such: 2, 1, 1, 4, 5, and 5 (the average was 3.0 ). In the decreasing condition, by contrast, the opponent decreased shock intensities as such: $4,5,5,2,1$, and 1 (the average was 3.0). The total amount of shocks was equal in both conditions. The dependent measure of retaliation was how intense the shocks that the subject delivered to his opponent were.
Eleven subjects were randomly assigned to each of these conditions.

Post-experimental questionnaire. The subject was asked to rate his opponent's personality in terms of seven 7-point rating scales. They were designed to measure the opponent's maliciousness: irrationalrational, rejecting-accepting, aggressiveunaggressive, cruel-kind, hostile-nonhostile, unfriendly-friendly, and competitivenoncompetitive.

Following completion of these procedures all subjects were debriefed regarding the opponent's role and the true purpose of this experiment. They were further asked to refrain from discussing the experiment with fellow students until sufficient time had passed to complete the study.

\section{Results}

Table 1 shows the subject's mean shock intensities in each of five shock trials. These scores were examined by an analysis of variance with one between (Attack Pattern) and one within (Shock Trial) effects. Attack Pattern was found to be nonsignificant $(F(1,20)=.20)$. The magnitude of retaliation was not different between the increasing attack condition and the decreasing attack condition. Shock Trial was also not significant $(F(4,80)=2.09)$, but the Attack Pattern $\times$ Shock Trial interaction was significant $(F(4,80)=3.44, \quad p<.025)$. There were significant differences among 
the trials only in the increasing attack condition. However, neither tendency for monotonous increase nor decrease in retaliation was found in either condition.

In analysis of the ratings of the opponent's maliciousness, each opponent's score was a simple sum of the rating values given to him on the seven scales. A highly significant $t$ value $(t=3.84$, $d f=20, \quad p<.01)$ clearly indicated that the subjects rated the opponent who had decreased attack $(M=31.3, \quad S D=3.52)$ as more malicious than the opponent who had increased attack $(M=25.8, S D=$ 2.85).

\section{Discussion}

The recency hypothesis predicted that the subjects' retaliation would be more intense in the increasing attack condition than the decreased condition. However, the results did not support this prediction. The subjects' total shock delivery was almost equal in both conditions. It favoured the equity view which predicted that the subjects would retaliate on their opponents in proportion to the total amount of attack which they had received.

Equity theorists assert that all participants in a relationship expect to receive equal relative outcomes from it and that if they perceive inequity, they will try to remove the inequity (Walster, Bersheid, \& Walster, 1976). Retaliation is regarded as an attempt to restore equity (Bersheid, Boye, \& Walster, 1968; Ross, Thibaut, \& Evenbeck, 1971). Since Hammurabi's Code, "an eye for an eye" has been an important norm regulating social interactions. By using the competitive aggression paradigm, empirical research has found that this norm of retaliation takes a role in the reciprocation of aggression among Western university students (e.g., Dengerink, O'Leary, \& Kasner, 1975; Epstein \& Taylor, 1967). And, Ohbuchi reported that both male and female Japanese students also tend to respond to physical attack according to this norm (Ohbuchi, 1979; Ohbuchi \& Oku, 1980).

The present study suggested that a victim's retaliation is determined by equity-restoring when there is no possibility of being re-attacked. However, it should be noted that the equity view was only adopted in this experiment as an alternative hypothesis through rejection of the recency hypothesis. In order to establish the equity view of retaliation, therefore, further comparisons among other various attack patterns seem to be necessary.

Now, why recency was not effective in the present experiment? This effect appears to be closely related to control of the attacker's behavior. With regard to reciprocation of liking, a number of studies have dealt with the recency effect or a related gain-loss effect (e.g., Aronson \& Linder, 1965; Mettee, 1971). The relevant result here is that a subject expresses more liking for an evaluator who began negatively but became positive (increasing liking) than for an evaluator who began positively but became negative (decreasing liking). Kelley (1972) interpreted this as that the subject attributes the increasing liking to himself, perceiving himself as having succeeded in exercising influence over his evaluator. In Taylor's standard paradigm, likewise, a subject who observes his opponent decrease attack level may regard it as evidence of his controlling the opponent. The subject of the present experiment, however, was not likely to feel so because the present procedure separated the attack and the retaliation sessions. Consequently, the present results suggest that recency is not important when the subject is induced to be relatively indifferent to control of the opponent's behavior.

An analysis of the rating of maliciousness revealed an unexpected result in that the subject rated the opponent who had 
decreased his attack as more malicious than the opponent who had increased his attack. Neither equity nor recency views can explain this result. In informal interviews after the experiment, some subjects in the decreasing condition said that they had been very surprised when their opponent had delivered very intense shocks in the initial phase of the attack session. It seems that there is a social norm that people should behave politely in the initial phase of contact with others. The subjects may have inferred the strong aggressiveness of the opponents because they behaved against the norm of politeness.

\section{References}

Aronson, E., \& Linder, D. 1965 Gain and loss of esteem as determinants of interpersonal attractiveness. Journal of Experimental Social Psychology, 1, 156-172.

Berscheid, E., Boye, D., \& Walster, E. 1968 Retaliation as a means of restoring equity. Journal of Personality and Social Psychology, 10, 370-376.

Dengerink, H. A. 1976 Personality variables as mediators of attack-instigated aggression. In R. G. Geen \& E. C. O'Neal (Eds.), Perspectives on aggression. New York: Academic Press. Pp. 61-98.

Dengerink, H. A., O'Leary, M. R., \& Kasner, K. H. 1975 Individual differences in aggressive responses to attack: Internal-external locus of control and field dependence-independence. Journal of Research in Personality, 9, 191-199.

Epstein, S., \& Taylor, S. P. 1967 Instigation to aggression as a function of degree of defeat and perceived aggressive intent of the opponent. Journal of Personality, 35, 265-289.

Gaebelein, J. W. 1978 Third party instigated aggression as a function of attack pattern and a nonaggressive response option. Journal of Research in Personality, 12, 274-283.

Kelley, H. H. 1972 Attribution in social interaction. In E. E. Jones, D. E. Kanouse, H. H. Kelley, R. E. Nisbett, S. Valins, \& B. Weiner (Eds.), Attribution: Perceiving the causes of behavior. Morristown: General Learning Press. Pp. 1-26.

Mettee, D. R, 1971 The true discerner as a potent source of positive affect. Journal of Experimental Social Psychology, 7, 292-303.

Ohbuchi, K. 1979 Hostility as unresponsiveness to friendly changes of opponent's behavior. Japanese Journal of Psychology, 50, 249-255. (In Japanese with English Summary)

Ohbuchi, K., \& Oku, Y. 1980 Aggressive behavior as a function of attack pattern and hostility. Psychologia, 23, 146-154.

O'Leary, M. R., \& Dengerink, H. A. 1973 Aggression as a function of the intensity and pattern of attack. Journal of Research in Personality, 7, 61-70.

Ross, M., Thibaut, J., \& Evenbeck, S. 1971 Determinants of the intensity of social protest. Journal of Experimental Social Psychology, 7, 401418.

Taylor, S. E., \& Fiske, S. T. 1978 Salience, attention, and attribution: Top of the head phenomena. In L. Berkowitz (Ed.), Advances in experimental social psychology, Vol. 11. New York: Academic Press. Pp. 250-289.

Taylor, S. P. 1967 Aggressive behavior and physiological arousal as a function of provocation and the tendency to inhibit aggression. Journal of Personality, 35, 297-310.

Walster, E., Bersheid, E., \& Walster, G. W. 1976 New directions in equity research. In L. Berkowitz \& E. Walster (Eds.), Advances in experimental social psychology, Vol. 9. New York: Academic Press. Pp. 1-42.

Zillman, D. 1979 Hostility and aggression. Hillsdale: Lawrence Earlbaum Associations.

(Received March 9, 1981 ; accepted July 4, 1981) 